Saudi Journal of Oral and Dental Research

Abbreviated Key Title: Saudi J Oral Dent Res

ISSN 2518-1300 (Print) |ISSN 2518-1297 (Online)

Scholars Middle East Publishers, Dubai, United Arab Emirates

Journal homepage: https://saudijournals.com/sjodr

\title{
Visionaries or Dreamers? Story of Parent's Perception, Attitude and Awareness about Children's Oral Health
}

\author{
Wajiha Alamgir ${ }^{1 *}$, Rabia Naseer ${ }^{2}$, Uzma Jabbar Khan ${ }^{3}$, Aroosa Ashraf ${ }^{4}$, Faheem Abrar ${ }^{5}$, Ali Farooq ${ }^{6}$ \\ ${ }^{1}$ Associate Professor, Oral Pathology \& Oral diagnostics, University of Lahore Pakistan \\ ${ }^{2}$ Assistant Professor Oral and Maxillofacial Surgery, University College of Dentistry, University College of Lahore \\ ${ }^{3}$ Senior Lecturer, Oral Pathology \& Oral Diagnostics, University of Lahore Pakistan \\ ${ }^{4}$ Demonstrator, Oral Pathology \& Oral Diagnostics, University of Lahore Pakistan \\ ${ }^{5}$ Dental Surgeons, Govt. Nawaz Sharif Hospital, Yakki Gate, Lahore Pakistan \\ ${ }^{6}$ Assistant Professor Oral and Maxillofacial Surgeries, College of Dentistry Sharif Medical and Dental College Lahore Pakistan
}

DOI: $10.36348 /$ sjodr.2020.v05i10.002 $\quad$ | Received: 12.09 .2020 | Accepted: 26.09 .2020 | Published: 10.10 .2020

*Corresponding author: Wajiha Alamgir

\section{Abstract}

Objective: To analyze the level of parents' perception, attitude and awareness about care of primary teeth. Methodology: A descriptive cross sectional study was conducted in general population with non-probability purposive sampling technique. Validated questionnaire was used consisting of 30 close ended questions. Total of one hundred and forty nine questionnaires $(n=149)$ were selected for the study. Questionnaire was divided into five domains: : 1) knowledge of parents, 2) attitude of parents towards care of primary teeth, 3) oral health practice of parents, 4) oral health practice of children and 5) psychosocial effects of poor oral hygiene of children. Result: The results revealed that the parents have minimal knowledge regarding the care of deciduous teeth. But parents are concerned about the oral hygiene of their children and early childhood caries as majority of them surmise that having an unpleasant appearance makes the child feel inferior and also affects the school performance. Conclusion: Improvement in the dental awareness of the parents as well as update the knowledge of the general dental practitioners is essential so that they can inculcate a positive dental attitude in the patients and parents. There is an urgent need to enhance the knowledge and train the parents to promote lifelong oral hygiene habits.

Keywords: primary teeth, early childhood caries, oral hygiene.

Copyright @ 2020: This is an open-access article distributed under the terms of the Creative Commons Attribution license which permits unrestricted use, distribution, and reproduction in any medium for non-commercial use (NonCommercial, or CC-BY-NC) provided the original author and source are credited.

\section{INTRODUCTION}

Oral health has a major influence on children's quality of life which in turn is essential for their optimum general physical health. Basic oral health practices should be incorporated as an essential agreement of daily routine right from early childhood to prevent oral health related issues [1]. Parental counselling plays a vital role in child's early years of life and considered as a potent social force for establishing child's wellbeing $[1,2]$. Parents especially mothers who are well equipped with knowledge and skills pertaining to maintenance of good oral health lead to development of effective oral hygiene practices in their children. Hence the fact indicates that parent's attitude, knowledge and skills exert positive impact on children's oral health [2]. Analogically, significance of primary teeth cannot be neglected being they are crucial for basic life functions such as mastication, speech, phonetics, esthetics as well as development and space maintenance for permanent teeth [3, 4]. Most frequently encountered problem in primary teeth are caries referred as 'early childhood caries' resulting in pain and difficulty in chewing which in turn decreases food leading to malnutrition [2]. An increased incidence of caries is seen in children on overnight bottle feeding due to high sucrose content in milk leading to tooth decay. In addition to functional complications, primary tooth caries can potentially result in several psychological consequences which may include compromised esthetics causing lack of confidence, social isolation, shyness, unhappiness and poor school performance [2, 3]. Parents particularly those with low socioeconomic background often neglect children's dental management due to a notion that primary teeth are temporary teeth and they will be replaced by a new set of dentition [3]. Therefore, interventions focusing on parental dental health knowledge may be favorable for preventing oral health issues in children [5]. 


\section{METHODOLOGY}

A descriptive cross sectional study was conducted in general population from November 2019 to April 2020. Non probability purposive sampling technique was used. The research was conducted following the approval by the Institutional Ethical Committee, University of Lahore. Informed consent was taken from all parents.

Inclusion Criteria: Both parents mothers and fathers, participated in the study having children below 12 years. Exclusion Criteria: Guardians, relatives, teachers or parents having children above 12 years of age were not included.

160 questionnaires were distributed in general population according to inclusion criteria. Dropout rate was $6.8 \%(\mathrm{n}=11)$ and 149 questionnaires were received back for data analysis.

The aim of our study was to analyze the level of parents' perception, attitude and awareness about care of primary teeth.

\section{Questionnaire}

The questionnaire contains demographic data which includes age, gender, residence (rural/urban) and level of education of the parents. 30 close ended questions were asked to evaluate the oral health practices and knowledge of parents about care of primary teeth. The questionnaire was divided into 5 domains which are as follow: 1) knowledge of parents, 2) attitude of parents towards care of primary teeth, 3) oral health practices of parents, 4) oral health practices of children and 5) psychosocial effects of poor oral hygiene of children.

\section{RESULTS}

A total of 160 parents participated in the study and 149 were selected for final analysis. 111 were mothers and 38 were fathers. 84 parents were from urban areas and 65 from rural areas. The level of education of parents ranged from primary education $(8.72 \%)$, middle education $(11.40 \%)$, intermediate $(18.12 \%)$, graduation $(33.55 \%)$, post-graduation $(15.43 \%)$ and $(12.75 \%)$ were illiterate.

\section{Knowledge of parents}

Out of total, $50.3 \%(n=75)$ parents agreed that a child needs to visit a dentist in every six months while $39 \%(n=58)$ had no knowledge about importance of monthly visits to dentist. Only $14 \%(\mathrm{n}=21)$ parents were aware about the commercially available tooth wipes. Nearly $59 \%(n=88)$ parents knew that excess sugar in diet, poor oral hygiene and sticky food stuff causes tooth decay. Moreover, a relatively less frequency of parents $(38.2 \%, \mathrm{n}=57)$ were aware of the availability of pediatric toothpaste in market. Majority $73.15 \%$ $(n=109)$ didn't have any knowledge regarding optimum fluoride concentration safer for children. The fact that bottle feeding at night harms child's teeth was acknowledged by $57.7 \% \quad(n=86)$ of parents. A large proportion of the parents $(62.4 \%, \mathrm{n}=93)$ knew that untreated primary teeth may cause serious illness. Nearly half number $(n=75,50.3 \%)$ of parents were aware of the fact that premature exfoliation or extraction of primary teeth will lead to malocclusion while $40.9 \%(n=61)$ had no knowledge regarding that. Furthermore, $43.6 \% \quad(n=65)$ parents believed that brushing child's teeth should be supervised till the age of five years and only $21.4 \%(n=32)$ are of the opinion that it should be supervised till age of eight years. Regarding medium of information about importance of child's oral health maintenance majority of the parents $(38.2 \%, \mathrm{n}=57)$ considered social media as the more reliable source followed by feedback from peers $(25.5 \%, \mathrm{n}=38)$ and discussion with family dentist $(22.8 \%, \mathrm{n}=34)$ [Table1].

Table-1: Frequency of parents about various realms of knowledge about child's oral health maintenance

\begin{tabular}{|c|c|c|c|}
\hline \multicolumn{4}{|c|}{ Knowledge of Parents } \\
\hline \multirow[t]{2}{*}{ Questions } & \multicolumn{3}{|c|}{ Frequency $(n=149)$} \\
\hline & Yes & No & Don't Know \\
\hline 1. Do a Child needs to visit a dentist in every six months? & $75(50.3 \%)$ & $16(10.7 \%)$ & $58(38.9 \%)$ \\
\hline $\begin{array}{l}\text { 2. Do you have information about commercially available Tooth } \\
\text { wipes? }\end{array}$ & $21(14 \%)$ & $18(12 \%)$ & $110(73.8 \%)$ \\
\hline 3. Do you have information about Pediatric Toothpaste? & $57(38.2 \%)$ & $19(12.7 \%)$ & $73(48.9 \%)$ \\
\hline 4. What Optimum Fluoride Concentration is safer for children? & $29(19.4 \%)$ & $11(7.3 \%)$ & $109(73.1 \%)$ \\
\hline 5. Does Bottle Feeding at night is harmful? & $86(57.7 \%)$ & $17(11.4 \%)$ & $46(30.8 \%)$ \\
\hline 6. Does untreated primary carious teeth lead to serious illness? & $93(62.4 \%)$ & $13(8.7 \%)$ & $43(28.8 \%)$ \\
\hline 7. Can premature exfoliation and extraction cause malocclusion? & $75(50.3 \%)$ & $13(8.7 \%)$ & $61(40.9 \%)$ \\
\hline \multicolumn{4}{|l|}{ 8. What are the reasons for Tooth Decay? } \\
\hline a. Excess sugar in diet/juices & \multicolumn{3}{|c|}{$19(12.7 \%)$} \\
\hline b. Poor oral hygiene & \multicolumn{3}{|c|}{$14(9.3 \%)$} \\
\hline c. Sticky food stuff & \multicolumn{3}{|c|}{$28(18.7 \%)$} \\
\hline d. All of the above & \multicolumn{3}{|c|}{$88(59 \%)$} \\
\hline
\end{tabular}


Wajiha Alamgir et al., Saudi J Oral Dent Res, October, 2020; 5(10): 505-512

\begin{tabular}{|l|c|}
\hline \multicolumn{1}{|c|}{ 9. Till what age child's teeth brushing should be supervised? } \\
\hline a. 5 years & $65(43.6 \%)$ \\
\hline b. 8 years & $32(21.4 \%)$ \\
\hline c. 10years & $42(28.1 \%)$ \\
\hline d. Don't know & $10(6.7 \%)$ \\
\hline 10. Which source of information is reliable about importance of child's oral health maintenance? \\
\hline a. Social media & $57(38.2 \%)$ \\
\hline b. Print media & $08(5.3 \%)$ \\
\hline c. Electronic media & $12(8 \%)$ \\
\hline d. Family dentist & $34(22.8 \%)$ \\
\hline e. Feedback from peers & $38(25.5 \%)$ \\
\hline
\end{tabular}

\section{Attitude of parents}

A large number of parents $(80.5 \%, n=120)$ acknowledged the fact that primary teeth are important for their child. Likewise, majority of the parents $(86.5 \%, \mathrm{n}=129)$ agreed that oral health maintenance of a child is parent's responsibility. Moreover, a greater proportion of parents $(83.8 \%, \mathrm{n}=125)$ agreed that taking care of child's teeth is as important as any other part of the body. On the contrary, maximum number of parents (40.9\%, $\mathrm{n}=61$ ) had no knowledge about when to schedule child's first dental visit. However, $26.1 \%$ $(n=39)$ of parents thought that it must be scheduled when all milk teeth have erupted in the mouth. Regarding child's bottle feeding, $40.2 \%(n=60)$ parents were of the opinion that a child should be bottle fed till the age of 1-2 years. Furthermore, $51.6 \%(n=77)$ of parents agreed that they would take a child for dental treatment in case of any decayed milk tooth while $18.1 \%(\mathrm{n}=27)$ denied any treatment for a decayed deciduous tooth [Table 2].

Table 2: Tendency of parent's attitude regarding maintenance of their children's oral health

\begin{tabular}{|c|c|c|c|}
\hline \multicolumn{4}{|c|}{ Attitude of Parents } \\
\hline \multirow[b]{2}{*}{ Questions } & \multicolumn{3}{|c|}{ Frequency $(n=149)$} \\
\hline & Yes & No & Don't Know \\
\hline 1. Are Primary teeth important? & $120(80.5 \%)$ & $04(2.6 \%)$ & $11(7.3 \%)$ \\
\hline 2. Maintenance of Oral Health is Parent's duty? & $129(86.5 \%)$ & $09(6 \%)$ & $11(7.3 \%)$ \\
\hline 3. Is child's Counseling done before first dental visit? & $101(67.7 \%)$ & $48(32.2 \%)$ & 00 \\
\hline $\begin{array}{l}\text { 4. Care of primary teeth is as important as any other } \\
\text { part of body? }\end{array}$ & $125(83.8 \%)$ & $24(16.1 \%)$ & 00 \\
\hline \multicolumn{4}{|c|}{ 5. When the Child's first visit to a dental clinic should be scheduled? } \\
\hline \multicolumn{2}{|l|}{ a. As soon as child first tooth erupts or before age of one year } & \multicolumn{2}{|c|}{$27(18.1 \%)$} \\
\hline \multicolumn{2}{|l|}{ b. When all milk teeth have erupted in the mouth } & \multicolumn{2}{|c|}{$39(26.1 \%)$} \\
\hline \multicolumn{2}{|l|}{ c. When all permanent teeth come in the mouth } & \multicolumn{2}{|c|}{$22(14.7 \%)$} \\
\hline \multicolumn{2}{|l|}{ d. Don't know } & \multicolumn{2}{|c|}{$61(40.9 \%)$} \\
\hline \multicolumn{4}{|l|}{ 6. Till what age child should be bottle fed? } \\
\hline \multicolumn{2}{|l|}{ a. $1-2$ years } & \multicolumn{2}{|c|}{$60(40.2 \%)$} \\
\hline \multicolumn{2}{|l|}{ b. 2-3 years } & \multicolumn{2}{|c|}{$64(43 \%)$} \\
\hline \multicolumn{2}{|l|}{ c. More than 3 years } & \multicolumn{2}{|c|}{$25(16.7 \%)$} \\
\hline \multicolumn{4}{|c|}{ 7. What will be your attitude on finding a cavity in baby tooth? } \\
\hline \multicolumn{2}{|l|}{ a. No treatment } & \multicolumn{2}{|c|}{$27(18.1 \%)$} \\
\hline \multicolumn{2}{|l|}{ b. Visit to a dentist for treatment } & \multicolumn{2}{|c|}{$77(51.6 \%)$} \\
\hline \multicolumn{2}{|l|}{ c. Wait for the complain of pain } & \multicolumn{2}{|c|}{$45(30.2 \%)$} \\
\hline
\end{tabular}

\section{Oral health practices of parents}

Nearly equal frequency of parents, $47.6 \%$ brushed once and twice daily $(\mathrm{n}=70$ and 71 respectively) and $4.6 \% \quad(n=7)$ brush their teeth occasionally. Miswak was used as a cleaning device other than tooth brush by $41.6 \%(n=62)$ of parents, toothpicks were used by $21.7 \%(n=32)$ and $5.3 \%(n=8)$ parents use tree bark. Only $2 \%(n=3)$ parents were using modern cleaning devices like waterpik. Frequency of mouthwash usage was very low with $8.7 \% \quad(n=13)$ parents using mouthwash once a day and $4.6 \%(n=7)$ using twice a day while $51 \% \quad(n=76)$ never used mouthwash [Fig.1]. 


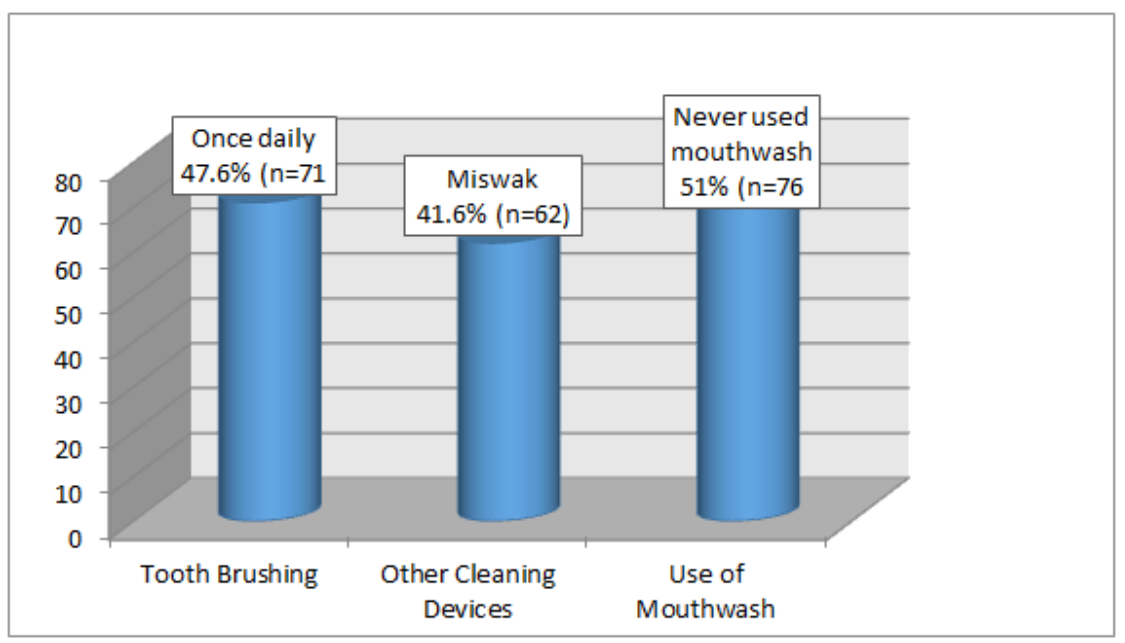

Fig-1: Frequency of widely held oral health practices among parents

\section{Oral health practices of children}

Out of the total, $80.5 \% \quad(\mathrm{n}=120)$ parents responded that they follow the practice of brushing their child's teeth while $6.7 \%(\mathrm{n}=10)$ never brushed their child's teeth. In addition, parents brushing their child's teeth once a day $(46.9 \%, \mathrm{n}=70)$ outnumbered those who brushed twice (39\%, $\mathrm{n}=58)$ and those who never brushed their child's teeth $(10.7 \%, \mathrm{n}=16)$. A larger proportion of the parents $(54.3 \%, \mathrm{n}=81)$ believed that they should start cleaning their child's mouth after all teeth undergo eruption whereas $30.8 \%(n=46)$ parents were of the opinion that it should be started after child's first tooth erupts and $14.7 \%(n=22)$ thought that tooth brushing should be commenced right from birth irrespective of presence or absence of teeth. Moreover, $52.3 \%(\mathrm{n}=78)$ parents claimed that they remain mindful about the presence of any cavity in their child's mouth while $32.8 \%(n=49)$ parents turned out not to be well aware about any such problems in their child's mouth [Fig.2].

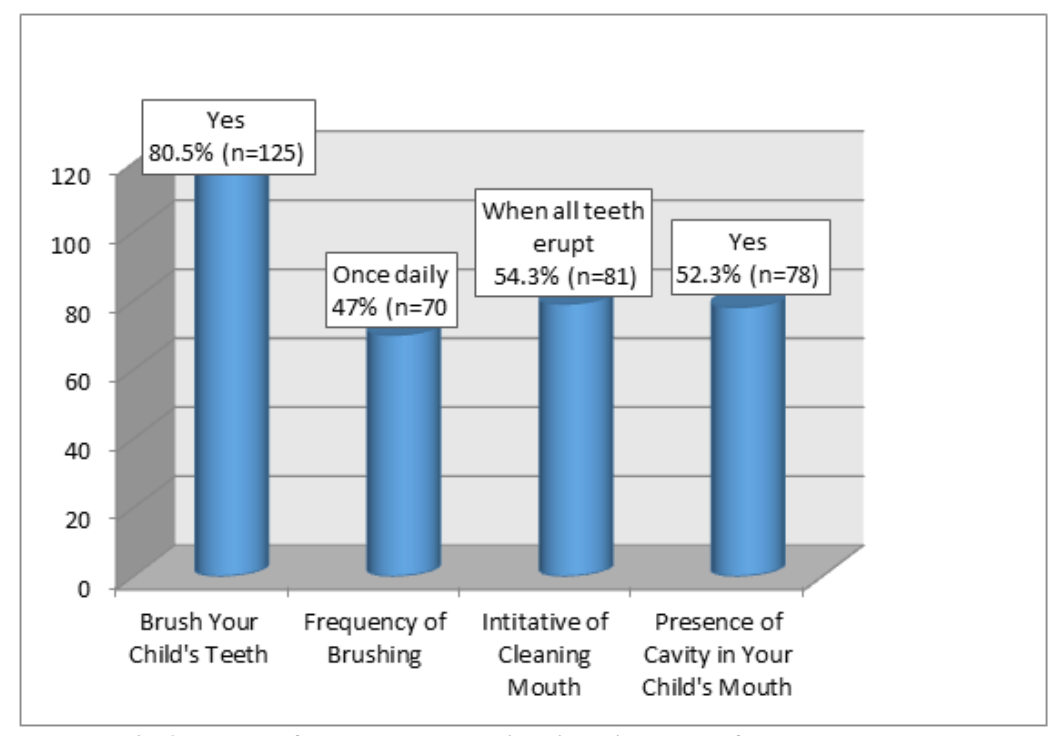

Fig-2: Trend of oral health practices in children performed by parents

\section{Psychosocial effects of poor oral hygiene}

Overall, a multitude of parents responded this domain with relatively greater concern yielding variable responses. Maximum number of parents $(77.1 \%$, $\mathrm{n}=115$ ) agreed upon the fact that poor oral hygiene makes children feel shy. Similarly, a preponderance of parents $(79.1 \%, \mathrm{n}=118)$ believed that poor oral hygiene makes children unhappy. Furthermore, $72.4 \%$ of parents $(n=108)$ were of the opinion that children feel inferior due to poor oral health. Out of total, majority of the parents $(63.7 \%, \mathrm{n}=95)$ agreed that poor oral hygiene affects school performance of children. Parents who believed that the child remains friendly in social interactions despite of poor oral health outnumbered $(58.3 \%, \mathrm{n}=87)$ those who surmised that children tend to adopt social isolation due to poor oral hygiene and unpleasant appearance of their teeth $(25.5 \%, \mathrm{n}=38)$. Moreover, $16.1 \%$ of parents $(n=24)$ suggested that child make occasional interactions due to poor oral health [Fig.3]. 


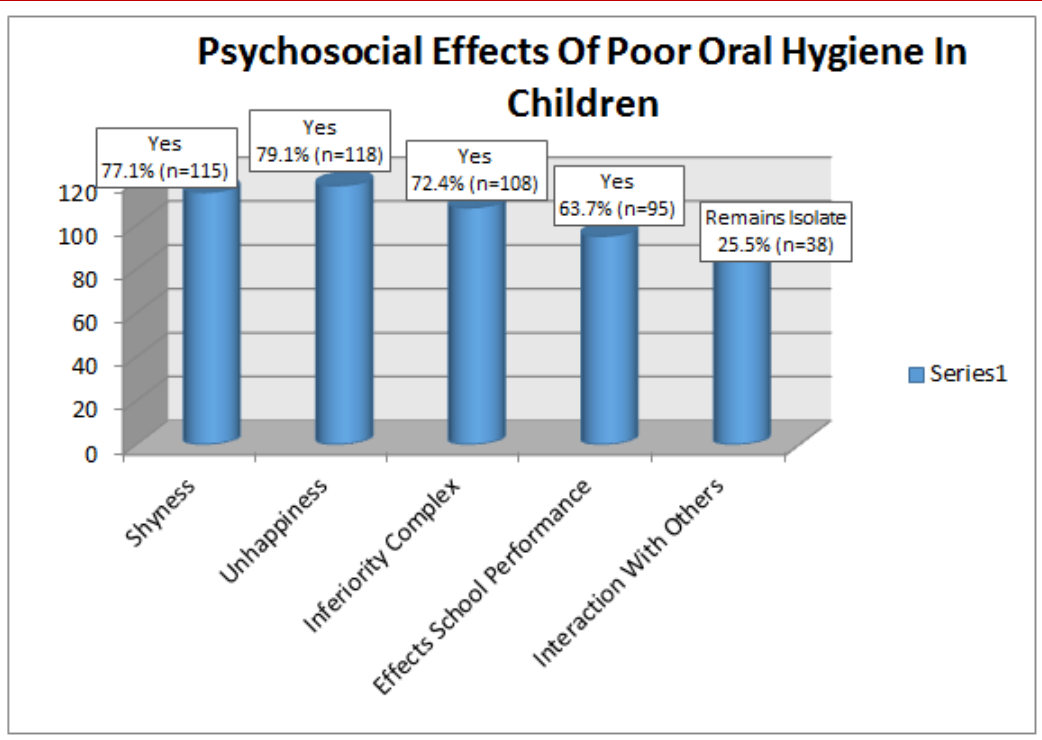

Fig-3: Frequency of psychosocial effects of poor oral hygiene in children

\section{DISCUSSION}

Maintenance of primary teeth health is very essential for general growth of a child. Parents are considered as an important source for maintaining child's wellbeing. Child's oral health status is determined through parent's attitude, knowledge and skills with respect to child's oral hygiene habits [2]. Parent's education regarding oral health of preschool and school children is of utmost importance because the oral health needs of children are dependent on them [6].

The present study was aimed at evaluation of parent's knowledge and attitude towards the care of primary teeth care of their children and also to assess oral health practices of parents who reported in the outpatient department of University College of Dentistry, University of Lahore.

Out of 149 respondents, 111 were mothers who accompanied their children at dental facility which showed that mothers are more involved in routine dental care of children as compared to fathers. Almost half of the respondents had high level of education, a finding which is consistent with the study conducted by Alsumait et al. [7].

When practices of oral hygiene maintenance among parents were assessed, it was found that majority parents brush once daily. Other than toothbrush, miswak was used as a cleaning device by numerous parents $(n=62,41.6 \%)$ as it is taken as ritualistic religious act in Muslim countries. Because of its easy availability, low cost and a part of tradition in developing countries, WHO also fostered its use in 1987 [8]. Along with the use of mechanical cleaning devices, mouthwash is also considered beneficial as an adjunct. However current study revealed an alarming low use of mouthwash showing very few parents $(n=23$, $15.4 \%$ ) using it on daily basis as an oral hygiene aid.
In the present study knowledge of parents was assessed regarding oral hygiene needs of their children. Nearly half of the respondents $(n=75,50.3 \%)$, in this study agreed that their child needs to visit a dentist once in every six months which is contrary to the results of study conducted by Nikhita, where $53 \%$ respondents disagreed that their child needs to visit a dentist every six months [9]. The American Academy of Pediatric Dentistry (AAPD) recommended that Oral hygiene practice should be carried out as soon as the first primary tooth erupts [10]. For this purpose tooth wipes have been recommended by AAPD (2008) for infants as an effective oral hygiene tool [11]. It is evident from literature that tooth wipes decreases bacterial colonization which in turn reduce the risk of dental caries [12]. In the study done by Shetty et al., $78.7 \%$ of parents were of the opinion that with eruption of first primary tooth, parents can begin cleaning the tooth by gauze or a clean piece of cloth [13]. In subject study, majority of the respondents $(n=110,73.8 \%)$ didn't know about commercially available tooth wipes.

In current study, about half of the parents $(\mathrm{n}=88,59 \%)$ had good knowledge about factors responsible for tooth decay such as excess sugar in diet, poor oral hygiene and sticky food stuff which is contrary to the result demonstrated by Salama et al. where $85 \%$ of respondents thought that sugary diet may increase the risk of dental caries [14]. Fluoride is considered as an important remedy for the control of dental decay and the most viable form for its administration is through the use of fluoridated toothpastes [6]. Over the counter available toothpastes containing $100 \mathrm{ppm}$ fluoride can lead to enamel fluorosis in future permanent teeth. According to the current results, a large number of parents $(n=109$, $73.1 \%$ ) had low level of awareness about the optimum fluoride concentration in toothpaste that is safer for children which is in accordance to the result of Shetty et 
al. where only $59.2 \%$ parents have knowledge in this regard [13].

Keeping in view the fact that infants tend to swallow the toothpaste, pediatric toothpaste with lesser amount of fluoride safer for children have been introduced [15]. In present study, around half of respondents were not aware about the availability of pediatric toothpastes in market. These results are somewhat similar to those depicted by Narayaman, where $75 \%$ parents had no knowledge about pediatric toothpastes [16].

Majority of parents $(n=86,57.7 \%)$ agreed that bottle feeding at night have a role in causing dental caries which is in line with the results shown by Shetty et al. where $53.9 \%$ mothers believed that bottle feeding leads to tooth decay [13]. Many complications and serious illness may arise as a result of untreated carious primary teeth such as infection, pain, difficulty in eating and malnutrition that may lead to altered development and growth. Early loss of teeth as a result of untreated primary teeth may ultimately lead to malocclusion of the permanent teeth as well [17]. In the present study, more than half of the respondents $(n=93,62.4 \%)$ were aware of the fact that untreated carious primary teeth may lead to serious illness and about $(n=75,50 \%)$ half number of parents had the knowledge regarding malocclusion caused by early exfoliation or extraction of primary teeth.

To ensure good oral hygiene, parents should supervise their child in brushing until they get proficient. According to American academy of pediatric dentistry (AAPD), child should be supervised by the age of eight years [8]. In this study, parents $(n=32$, $21.9 \%$ ) thought that supervised brushing should be done till the age of eight years which is somewhat similar to the results of Jasmine et al. where $48.2 \%$ of the parents agreed that supervision of brushing is needed till age 78 years [18]. The present study found that $(n=57$, $38.2 \%$ ) parents believed that social media is the most popular source of child's oral health knowledge which is contradictory to the findings of Shetty et al., where majority of the mothers considered elders in the family as a source of getting knowledge regarding child's oral health [13].

Parents were questioned about the oral health practices of children, where significant number of parents claimed that they brush their child's teeth. Brushing twice daily, once in morning and once at night before going to bed is an important habit for maintenance of good oral hygiene [18]. In the present study $39 \%$ of parents brush their child's teeth twice daily whereas $47 \%$ brush only once a day. This out-turn is comparable to the results of Singhal et al., where $42 \%$ parents brush their child's teeth twice and 56\% brush once daily [19]. Majority of the parents $(n=81$, $54.3 \%$ ) in current study were having impression that cleaning child's mouth should be started after the eruption of all teeth, which is contradictory to the findings of Shetty et al. where $78.7 \%$ parents believed that cleaning should be commenced with the eruption of child's first tooth [13]. Nearly half of the respondents $(\mathrm{n}=78,52.3 \%)$ agreed that their child was having cavities in their mouth which support the fact that they were well aware of the child's oral health status.

While assessing the attitude of parents towards the importance of primary teeth, it was found that a preponderance of parents $(n=120,80.5 \%)$ agreed that primary teeth are important for their child's wellbeing. The finding is consistent with that of Abu bakar et al. where $86.1 \%$ parents thought that primary teeth are as important as permanent teeth [20]. A large proportion of participants $(n=129,86.5 \%)$ agreed with the fact that the maintenance of child's oral health is the duty of parents whereas $9(6 \%)$ respondents answered in denial. First dental visit is an important event in child's life and is crucial for the general health care of children. Regarding scheduling the dental visit, majority parents in the present study didn't know when to schedule the first dental visit of a child which is in parallel to the findings of Kumar et al. [21] and Sultan et al. [22]. It is recommended by American Academy of Pediatric Dentistry (AAPD) that initial dental visit of a child should be made before completion of 1 year of age or within six months of eruption of primary teeth [23, 24]. In current study, $43 \%$ parents $(n=64)$ were of the opinion that children should be bottle fed till 2-3 years of age followed by $40.2 \%$ parents $(n=60)$ who thought that the habit must be continued till 1-2 years of age. Least number of parents $(n=25,16.7 \%)$ were having the concept to continue bottle feeding more than 3 years of age. These findings are in accordance to American Academy of Pediatric Dentistry guidelines which state that infant should be encouraged to drink from cup at six months of age and by one year bottle feeding should be discouraged [25]. Moreover, it was encouraging to find out that a large number of parents $(n=125,83.8 \%)$ in this study agreed upon the fact that taking care of child's teeth is as important as any other part of the body which is similar to the results of the study conducted by Mahmoud et al. where $55.7 \%$ respondents have the same thought [26].

Compromised oral hygiene adversely affects child's quality of life. Poor oral health causes poor general physical health and lead to many psycho-social problems such as poor school performance and cynical social life of a child [27]. In present study $(n=95$, $63.7 \%$ ) parents believed that poor oral health affects their child school performance whereas in a study conducted by Herrano et al., the results showed that $30.54 \%$ parents agreed that poor oral hygiene affects the school performance [28]. In the current study, majority respondents believed that apart from school performance of children, poor oral health also makes children feel shy, unhappy and makes them feel inferior 
to others which is in contrast to the findings of Herrano et al. where $70.9 \%$ respondents believed that children never feel shy, $59.43 \%$ said that they don't feel inferior, $49.89 \%$ thought that poor oral hygiene don't make children unhappy and $55.41 \%$ responded that they remain friendly [28].

The present study has collected the information regarding the knowledge and attitude of parents towards primary teeth. Most parents despite of the high literacy level, lack knowledge in some important areas which is a matter of deep concern. The results of the present study may be beneficial to dental fraternity in counselling and educating the parents.

\section{CONCLUSION}

The present study reflects lack of knowledge and awareness on the part of parents regarding fluoride, pediatric toothpastes and tooth wipes. Attitude of parents regarding child's first dental visit and overall health status of primary teeth was also deplorable. Whereas many parents had knowledge about the effect of diet on oral health and were aware of the oral health status of their children. However parent's attitude, behavior and oral health practices pretend towards rectification. Parents play a consequential role in wellbeing of a child therefore; there is an obligation to provide an impetus on children's oral health education and promotion in order to maintain an optimum proper oral health status of children.

\section{RECOMMENDATIONS}

The American Academy of Pediatric Dentistry (AAPD) recommends that:

All primary health care professionals who serve mothers and infants should provide parent/ caregiver education on the etiology and prevention of early childhood caries. Every infant should receive an oral health risk assessment from his/her primary health care provider or qualified health care professional by 6 months of age. Parents or caregivers should establish a dental home for infant by 12 months of age for providing education on infant oral health; and evaluating and optimizing fluoride exposure. Legislators, policy makers, and third party payers should be educated about the benefits of early interventions in order to support efforts that improve access to oral health care for infants and children [29].

\section{REFERENCES}

1. Sami, A., Fatima, K., Moin, H., Bashir, R., \& Ahmed, J. (2016). Relationship of parental knowledge and attitude with oral health status of children in Karachi east. BJMMR, 14(9), 1-9.

2. Vittoba, S. J., \& Srinivasan, I. (2016). Knowledge and Awareness of Primary Teeth and their Importance among Parents in Bengaluru City, India. Int J Clin Pediatr Dent, 9(1), 56-61.
3. Ramakrishnan, M., Banu, S., Ningthoujam, S., \& Samuel, V.A. (2019). Evaluation of knowledge and attitude of parents about the importance of maintaining primary dentition - A cross-sectional study. J Family Med Prim Care, 8(2), 414-418.

4. Mi Lee, S., Na kim, H., \& Bom kim, J. (2019). Association between maternal and child oral health and dental caries in Korea. J.Public Health, 27, 219-227.

5. Al Batayneh, O. B., Al Khanteeb, H. O., Ibrahim, W. M., \& Khader, Y. S. (2019). Parental knowledge and acceptance of different treatment options for primary teeth provided by dental practitioners. Front Public Health, 7, 322.

6. Khandun, N., Singhai, N., Mitra, M., \& Rohatgi, S. (2018). Knowledge, attitude and practices of parents towards their children's oral health: A questionnaire survey in Bhairahawa (Nepal). Ijpr, 3(2), 59-61.

7. Alsumait, A., Elsalhy, M., Raine, K., Cor, K., Gokiert, R., Al Mutawa, S., \& Amin, M. (2015). Impact of dental health on children's oral health related quality of life: a cross-sectional study. Health Qual Life Outcomes, 13(1), 98.

8. Patel, P.V., Shruti, S., \& Kumar, S. (2012). Clinical effect of miswak as an adjunct to toothbrushing gingivitis. J Indian soc Periodontol, 16(1), 84-88.

9. Narayanan, N. (2017). Knowledge and Awareness regarding primary teeth and their importance among parents in chennai city. J. Pharm. Sci. \& Res, 9(2), 212-214.

10. Al-Zahrani, A.M., Al-Mushayt, A.S., Otaibi, M.F., \& Wyne, A.H. (2014). Knowledge and attitude of Saudi mothers towards their preschool children's oral health. Pak J Med Sci, 30(4), 720-724.

11. Zhang, L., Cheng, J., Chang, P., Ngo, M., Denbesten, P.K., Hoover, C.I., \& Faetherstone, J.D. (2012). Effects of xylitol wipes on cariogenic bacteria and caries in young children. J.Dent.Res, 91(7), 855-905.

12. Aishunaiber, R., Alzaid, H., Meaigel, S., Aldeeri, A., \& Adlan, A. (2019). Early childhood caries and infant's oral health; pediatricians and family physician's practice, knowledge and attitude in Riyadh city, Saudi Arabia. sdentj, 31, 596-5105.

13. Shetty, R.M., Deoghare, A., Rath, S., sarda, R., \& Tamrakar, A. (2016). Influence of mother's oral health care knowledge on oral health status of their preschool child. J Oral Sci, 3(1), 12-16.

14. Salama, A.A., Konsowa, E.M., \& Alkalash, S.H. (2020). Mother's knowledge, attitude and practice regarding their primary school children's oral hygiene. Menoufia Med J, 33(1), 11-17.

15. Shinde, P.P., Shetiya, S.H., Agarwal, D., \& Mathur, A. (2018). Knowledge, attitude and practice about infant oral hygiene care among indian professional working mothers: A questionnaire study. Jiaphd, 16(1), 58-61.

16. Narayaman, N. (2017). Knowledge and awareness regarding primary teeth and their importance 
among parents in Chennai city. J.Pharm Sci \& Res, 9(2), 212-214.

17. Setty, J.V., \& Srinivasan, I. (2018). Knowledge and awareness of primary teeth and their importance among parents in Bengaluru city, India. IJCPD, 9(1), 56-61.

18. Winnier, J.J., Parmar, A., Mehta, S., Bambal, K., \& Bhatia, R. (2015). Oral hygiene maintenance in children - A survey of parental awareness. Int $J$ Oral Health Med Res, 2(4), 1-5.

19. Singhai, K., Singh, V., \& Choudhary, R. (2015). Knowledge, attitude and practices of parents about child oral health in Jodhpur city: A questionnaire survey. Int $j$ dent med res, 1(6), 37-41.

20. Abu Bakar, N.A., \& Mamat, Z. (2018). Parental knowledge and practices on preschool children oral health care in Nibong Tebal Penang, Malaysia. JOJNHC, 7(4), 1-5.

21. Kumar, G., Dhillon, J.K., Vignesh, R., \& Garg, A. (2019). Knowledge, attitude and practical behavior of parents regarding their child's oral health New Delhi. J Indian Pedod prev dent, 37(1), 3-7

22. Sultan, S., Ain, T.S., \& Gowhar, O. (2016). Awareness of mothers regarding oral health of their children in Kashmir, India. Ijcmr, 3(7), 2168-2171.

23. Khanal, K., Shrestha, D., Ghimire, N., Younian, R., \& Saniel, S. (2015). Assesment of knowledge regarding oral hygiene among parents of preschool children attending pediatric outpatient department in Dhulikhel hospital. KUMJ, 13(49), 38-43.

24. Djordjevic, A. (2018). Parent's knowledge about the effects of oral hygiene, proper nutrition and fluoride prophylaxis on oral health in early childhood. Balk j dent med, 22, 27-31.

25. Suwansingha, O., \& Rirattanapong, P. (2014). Preschool children's caregivers' attitudes and behavior regarding bottle feeding in Bangpakong, Chachoengsao.J Int Soc Prev Community Dent, 4(2), 93-98.

26. Mahmoud, K., Al-Omiri., Al-Wahadni, A.M., \& Saeed, K.N. (2006). Oral health attitudes, knowledge, and behavior among school children in North Jordan. J. Dent. Educ., 70(2), 179-187.

27. Oyedele, T.A., Folayan, M.O., \& Onyejaka, N.K. (2019). Social predictors of oral hygiene status in school children from suburban Nigeria. Braz oral res, 33 .

28. Herrano, G., \& Wehby, G.L. (2012). Children's dental health, school performance and psychological wellbeing. J Pediatr, 161(6), 11531159.

29. Dhull, K.S., Indira, M.D., Dhull, R.S., Sawhney, B. (2016). Infant Oral Health Care: An Invaluable Clinical Intervention. Indian J dent. 1(3), 8. 